\title{
BOUNDED RATIONALITY AND STRATEGIC COMPLEMENTARITY IN A MACROECONOMIC MODEL: POLICY EFFECTS, PERSISTENCE AND MULTIPLIERS
}

Antúlio N. Bomfim

Francis X. Diebold

Working Paper 5482

\author{
NATIONAL BUREAU OF ECONOMIC RESEARCH \\ 1050 Massachusetts Avenue \\ Cambridge, MA 02138 \\ March 1996
}

Helpful comments were provided by Martin Baily, Russell Cooper, Allan Drazen, David Gordon, John Haltiwanger, Peter Tinsley, and two anonymous referees, as well as by seminar participants at the North American Winter Meetings of the Econometric Society, the University of Maryland, and the Federal Reserve Board. All remaining errors are ours. We thank the National Science Foundation, the Sloan Foundation, the University of Pennsylvania Research Foundation, the Institute for Empirical Macroeconomics and the Federal Reserve Bank of Philadelphia for support. This paper is part of NBER's research program in Economic Fluctuations. Any opinions expressed are those of the authors and not those of the Federal Reserve Board, members of its staff, or the National Bureau of Economic Research.

(C) 1996 by Antúlio N. Bomfim and Francis X. Diebold. All rights reserved. Short sections of text, not to exceed two paragraphs, may be quoted without explicit permission provided that full credit, including $\odot$ notice, is given to the source. 


\title{
BOUNDED RATIONALITY AND STRATEGIC COMPLEMENTARITY IN A MACROECONOMIC MODEL: POLICY EFFECTS, PERSISTENCE \\ AND MULTIPLIERS
}

\begin{abstract}
Motivated by recent developments in the bounded rationality and strategic complementarity literatures, we examine an intentionally simple and stylized aggregative economic model, when the assumptions of fully rational expectations and no strategic interactions are relaxed. We show that small deviations from rational expectations, taken alone, lead only to small deviations from classical policy-ineffectiveness, but that the situation can change dramatically when strategic complementarity is introduced. Strategic complementarity magnifies the effects of even small departures from rational expectations, producing equilibria with policy effectiveness, output persistence and multiplier effects.
\end{abstract}

Antúlio N. Bomfim

Federal Reserve Board

20th and Constitution Avenue, NW

Washington, DC 20551
Francis X. Diebold

Department of Economics University of Pennsylvania 3718 Locust Walk Philadelphia, PA 19104-6297 and NBER 


\section{Introduction}

Recent work has suggested the potential importance of boundedly-rational expectations and strategic complementarity for macroeconomics, but the associated literature is primarily microeconomic and game theoretic. In this paper we take a different and complementary approach, exploring and illustrating the effects of bounded rationality and strategic complementarity in an intentionally simple and stylized aggregative economic model, very much in the tradition of the one used by Sargent and Wallace (1975). This provides a simple framework to examine and to illustrate the macroeconomic effects of bounded rationality and strategic complementarity, and to contrast our results with the well-known stark results obtained under classical conditions.

We present our results in a series of richer analyses. In section 2, we first present the standard classical results under rational expectations and no strategic interactions -- monetary policy is ineffective and output displays no persistence. We then relax the assumption of fullyrational expectations while still denying the possibility of strategic complementarity. Accordingly, we assume that the economy is populated by two types of agents: sophisticated forecasters form rational expectations, and rule-of-thumb forecasters use a simple forecasting rule. We show that, although monetary policy can be effective and output can display persistence, the amount of boundedly-rational ("rule-of-thumb") expectations formation needed to generate realistic outcomes is implausibly large. In section 3 , we study the model with both heterogenous expectations and strategic complementarity and show that policy effectiveness and output persistence are obtained even when only a very small amount of rule-of-thumb behavior is present. In particular, we show that the interaction of bounded rationality and strategic complementarity produces a disproportionately large impact of rule-of-thumb behavior. In 
section 4, we lend quantitative precision to the theoretical results by computing the response of output, money and prices to a unit supply shock, under a variety of parameter values. We conclude in section 5 .

\section{A Stylized "New-Classical" Model}

\subsection{Rational Expectations}

Following the well-known work of Lucas $(1972,1973,1975)$, let the log of output per capita supplied by sector $\mathrm{i}, \mathrm{i}=1, \ldots, \mathrm{N}$, be given by

$$
Y_{i t}=\alpha\left(P_{i t}-P_{i}\right)+u_{i t}
$$

where $Y_{i t}$ denotes $\log$ output per capita in sector $i$ at time $t ; P_{i t}$ is the $\log$ price in sector $i$ at time $t$; $P_{1}$ is the expectation (formed at time $t-1$ in sector $i$ ) of the log aggregate price level $P_{t}$ at time $t ; u_{i t}$ is a zero-mean sector-specific stochastic supply shock at time $t$; and $\alpha$ is a supply response parameter, constant over space and time. Throughout this paper, all variables are measured as deviations from trend.

Aggregation yields the well-known Lucas supply function,

$$
Y_{1}=\alpha\left(P_{1}-P_{1}\right)+u_{1}
$$

Following Sargent and Wallace (1975), we incorporate this supply function, along with the rational expectations assumption that $P_{t}=E\left(P_{t} \mid I_{t-1}\right)$, in a simple and stylized macroeconomic model of money, output and the price level. We write

$$
\begin{gathered}
Y_{1}=\alpha\left(P_{1}-P_{f}\right)+u_{1} \\
M_{t}-P_{1}=Y_{t}+v_{t} \\
M_{t}=\beta P_{M}+W_{1},|\beta|<1
\end{gathered}
$$




$$
\begin{gathered}
3 \\
\mathbf{P}_{\mathrm{t}}=\mathrm{E}\left(\mathrm{P}_{\mathrm{t}} \mid \mathrm{I}_{\mathrm{t}-1}\right),
\end{gathered}
$$

where $\mathrm{M}$ and $\mathrm{P}$ denote the logs of the price level and nominal money stock, respectively, and $u, v$ and $w$ are zero-mean stochastic shocks, uncorrelated over space and time. Equation (3a) is the Lucas supply schedule discussed above. (3b) is a simple demand function for real money balances. (3c) is a simple feedback rule for the nominal money stock.'

The assumption of rational expectations implies that agents' forecasts are sophisticated enough to be fully model-consistent. Let us now show how these agents solve the model.

Equating the nominal demand for money (3b) and the supply of money (3c), and using (3a) and (3d) to eliminate $Y_{t}$ and $P_{b}^{e}$, we have the pseudo-reduced form for $P_{b}$,

$$
P_{t}=[\beta /(1+\alpha)] P_{t-1}+[\alpha /(1+\alpha)] E\left(P_{t} \mid I_{t-1}\right)+z_{t},
$$

where $z_{1}=\left(w_{1}-u_{1}-v_{1}\right) /(1+\alpha)$ is zero-mean white noise. In this model, because all agents are sophisticated forecasters, the aggregate expectation $\left(\mathrm{P}_{1}^{\mathrm{e}}\right)$ is just the conditional expectation of (4), and the aggregate price surprise is given by

$$
P_{1}-P_{1}^{e}=z_{1}
$$

Finally, inserting (5) into the aggregate supply equation (3a), we obtain the solution for aggregate output,

$$
Y_{t}=\alpha z_{t}+u_{1}
$$

Three well-known properties of the solution are apparent. First, monetary policy is ineffective, as evidenced by the fact that the feedback-rule parameter $\beta$ does not affect the equilibrium output path. Second, the equilibrium output path displays no persistence; output

${ }^{1}$ Other feedback rules are of course possible. We have, for example, also experimented with a monetary rule that feeds back on lagged output. Our basic conclusions remain unaltered. 
vibrates randomly around its natural rate. Third, the shocks $u_{t}, v_{1}$ and $w_{t}$ do not produce multiplier effects. $^{2}$

\subsection{Bounded Rationality}

In the tradition of Simon (1982), Mankiw (1985), Akerlof and Yellen (1985a, 1985b), and many others, it seems likely that at least some agents may adopt rule-of-thumb procedures for expectations formation. For instance, these agents might find it too costly to form rational expectations and choose instead to rely on less expedient rules of thumb -- see, e.g., Evans and Ramey (1992), and Sethi and Franke (1995). ${ }^{3}$ Therefore, as in Haltiwanger and Waldman (1989), we will now allow for the possibility that some agents (perhaps a very small subset of all agents) do not form expectations rationally.

It is a simple matter to allow some agents to form expectations via rules of thumb. We change (3d) to

$$
\mathrm{P}_{1}=(1-\eta) E\left(P_{t} \mid I_{1-1}\right)+\eta P_{i}^{*}, \quad 0 \leq \eta \leq 1,
$$

where $P_{1}^{*}$ denotes an expectation of time-t price, formed at time $t-1$ by any rule-of-thumb method.

We adopt a simple rule of thumb for expectations formation ${ }^{4}$,

${ }^{2}$ That is, the "impact multipliers" are less than one in absolute value, and all remaining multipliers are 0 . The impact multiplier for $u$ is $1 /(1+\alpha)$, for $w$ is $\alpha /(1+\alpha)$, and for $v$ is $-\alpha /(1+\alpha)$.

${ }^{3}$ Evans and Ramey (1992) and Sethi and Franke (1995) feature models where the costs of forming rational expectations are incorporated explicitly and show the existence of equilibria where rational and rule-of-thumb expectations coexist.

4 This so-called "regressive" expectations scheme enables us to make our points simply and effectively. Our basic results, however, remain unaltered for other simple non-rational rules of thumb, such as adaptive expectations. 


$$
\mathrm{P}_{\mathrm{t}}^{*}=\mathrm{P}_{\mathrm{t}-1} .
$$

Thus, the modified model is

$$
\begin{gathered}
Y_{t}=\alpha\left(P_{t}-P_{t}^{f}\right)+u_{t} \\
M_{t}-P_{t}=Y_{t}+v_{t} \\
M_{t}=\beta P_{t-1}+w_{t}, \quad|\beta|<1 \\
P_{t}^{e}=(1-\eta) E\left(P_{t} \mid I_{t-1}\right)+\eta P_{t-1}, \quad 0 \leq \eta \leq 1 .
\end{gathered}
$$

Let us now solve the modified model (3a), (3b), (3c) and (3d'). Again using (3b) and (3c) to eliminate $M$, and now using (3a) and (3d') to eliminate $Y_{1}$ and $P_{1}$, we have the pseudo-reduced form for $P_{t}$,

$$
P_{t}=[(\beta+\alpha \eta) /(1+\alpha)] P_{t-1}+[\alpha(1-\eta) /(1+\alpha)] E\left(P_{t} \mid I_{t-1}\right)+z_{t}
$$

After some tedious algebra, we obtain the aggregate price surprise,

$$
P_{1}-P_{1}^{e}=[\eta(\beta-1) /(1+\alpha \eta)] P_{t-1}+z_{1},
$$

and the equilibrium output process,

$$
Y_{t}=[\alpha \eta(\beta-1) /(1+\alpha \eta)] P_{t-1}+\alpha z_{1}+u_{t} .
$$

Policy is now effective (the feedback-rule parameter $\beta$ affects the equilibrium output sequence), and output displays persistence. ${ }^{5}$ However, it is clear from (6') that for small $\eta$, deviations from the classical results will be small. That is, "near-rational" expectations produce "near-classical" equilibria.

\section{A Stylized "New-Keynesian" Model}

\subsection{The Model}

${ }^{3}$ As before, however, all impact multipfiers are less than 1 in absolute value. 
In the model of heterogenous expectations sketched so far, large deviations from rationality are needed to produce equilibria with Keynesian features. ${ }^{6}$ Now we introduce the notion of strategic complementarity in our basic model. We then proceed to study the way in which strategic complementarity magnifies the effects of bounded rationality.

Strategic complementarity is present if the returns to engaging in some economic activity depend positively on the aggregate level of that activity. Cooper and John (1988) discuss a variety of models in which strategic complementarities arise. Diamond's (1982) model of search externality is a classic example; in Diamond's model, the likelihood of finding a suitable trading partner increases with the level of aggregate activity. Other scenarios that give rise to strategic complementarities include external increasing returns in the production function (e.g., Baxter and King, 1991) and imperfect competition (e.g., Hart, 1982, Heller, 1986, and Pagano, 1990). ${ }^{7}$

In our highly stylized model, we will capture the main thrust of the strategic complementarity literature by including aggregate output as a determinant of sectoral supply. We write

$$
Y_{i t}=\alpha\left(P_{i t}-{ }_{i} P_{i}\right)+s Y_{1}+u_{i t}, 0 \leq s<1,
$$

or in the aggregate,

$$
Y_{1}=\alpha\left(P_{1}-P_{D}\right)+s Y_{t}+u_{t}
$$

${ }^{6}$ This notion has a direct analog in the menu-cost literature, where under classical conditions, only large menu costs are capable of producing macroeconomically important effects (Ball, Mankiw and Romer, 1988; Ball and Romer, 1990). For instance, in Ball and Romer's framework, rigidities in real prices are needed to amplify the effects of small nominal frictions. As we will show, strategic complementarity plays a similar role in our model.

${ }^{7}$ Other contributions to the strategic complementarity literature include Haltiwanger and Waldman (1985, 1991), Oh and Waldman (1990, 1994), Cooper and Haltiwanger (1993), Chatterjee, Cooper, and Ravikumar (1993), and Sethi and Franke (1995), among others. 
where the parameter $s$ indexes the amount of strategic complementarity in the economy.

Rearranging yields the supply schedule

$$
Y_{1}=\gamma\left(P_{1}-P_{1}^{e_{1}}\right)+e_{t}
$$

where $\gamma=\alpha /(1-s)$ and $e_{t}=u_{t} /(1-s)$.

The complete macroeconomic model with strategic complementarity and bounded

rationality is then

$$
\begin{gathered}
Y_{1}=\gamma\left(P_{t}-P_{1}^{e}\right)+e_{t} \\
M_{t}-P_{t}=Y_{t}+v_{t} \\
M_{t}=\beta P_{t-1}+w_{t}, \quad 0<\beta<1 \\
P_{t}^{e}=(1-\eta) E\left(P_{t} \mid I_{t-1}\right)+\eta P_{t-1}, \quad 0 \leq \eta \leq 1 .
\end{gathered}
$$

Solving the modified model ( $\left.3 \mathrm{a}^{\prime \prime}\right),(3 \mathrm{~b}),(3 \mathrm{c})$ and $\left(3 \mathrm{~d}^{\prime}\right)$, we obtain the pseudo-reduced form for $P_{1}$

$$
P_{1}=[(\beta+\gamma \eta) /(1+\gamma)] P_{t-1}+[\gamma(1-\eta) /(1+\gamma)] E\left(P_{1} \mid I_{t-1}\right)+z_{t}
$$

In order to solve the model, the sophisticated forecasters take conditional expectations of ( $\left.4^{\prime \prime}\right)$ and solve it for $E\left(P_{t} \mid I_{t-1}\right){ }^{8}$ Thus the aggregate price surprise is

$$
P_{1}-P_{1}^{e}=[\eta(\beta-1) /(1+\gamma \eta)] P_{t-1}+z_{1}
$$

Insertion of ( $\left.8^{\prime \prime}\right)$ into ( $\left.3 a^{\prime \prime}\right)$ gives

$$
Y_{1}=[(\gamma \eta(\beta-1)) /(1+\gamma \eta)] P_{t-1}+\gamma z_{1}+e_{1}
$$

It is apparent that policy is effective, output displays persistence, and there are potential

\footnotetext{
${ }^{8}$ Note that when the rational-expectations agents use the conditional expectation of (4") to come up with their optimal forecasts, they are in effect incorporating the particular rule of thumb used by their counterparts with bounded rationality into their own forecasts. This feature of the model is akin to the "forecasting the forecast of others" notion discussed in Townsend (1983).
} 
multiplier effects. Accordingly, for any $\eta$, no matter how small, systematic monetary policy can be non-neutral. Thus, unlike (6'), equation (6") implies that even small values of $\eta$ can potentially lead to large deviations from classical results. Moreover, deviations of output from its natural rate can be highly persistent if strategic complementarity is large enough. Strategic complementarity works to amplify the effects of the rule-of-thumb agents, by making it optimal for all agents, rational and rule-of-thumb, to respond to nominal shocks.

It is important to note that the Keynesian features do not arise because of the strategic complementarity per se. They are the outcome of the interaction of the strategic complementarity with the boundedly-rational expectations. To see this, suppose that strategic complementarity exists but that expectations are rational $(s>0, \eta=0)$. Then

$$
Y_{1}=\gamma z_{1}+e_{1}
$$

Policy is ineffective and no persistence is generated.

\subsection{Additional Discussion}

It is of interest to examine the effects of $\eta$ and $s$ on various key properties of the model. This will allow us to quantify the algebraic results derived so far and to effectively run a sensitivity analysis on the $\eta$ and s parameters.

Response of Output to Lagged Prices. It follows from (6") that, for any fixed $\eta$, the response coefficient on lagged price is $[(\gamma \eta(\beta-1)) /(1+\gamma \eta)]$, the absolute value of which is monotonically increasing in $\mathrm{s}$ as illustrated in figure 1.9 Similarly, figure 1 also shows that, for any fixed $\mathrm{s}$, the

\footnotetext{
${ }^{9}$ Throughout this paper, we set $\alpha=.6$ and $\beta=-.2$ for illustrative purposes. In addition, we set the variances of all shocks to 1.0 .
} 
absolute response is monotonically increasing in $\eta$. Thus, strategic complementarity plays an important role in strengthening the intertemporal linkage between output and prices, and the higher the degree of complementarity, the stronger will this linkage be.

Policy Effects. We showed above that with bounded rationality and strategic complementarity, the monetary policy parameter, $\beta$, appears in the reduced form for output. This occurs because the expectations of the rule-of-thumb agents are not model-consistent and thus fail to adequately capture the systematic component of the monetary policy rule. Moreover, because of the multiplier effects implied by strategic complementarity, the expectational mistakes of these agents are magnified at the macroeconomic level. Therefore, even changes in policy that are well anticipated by the rational-expectations agents can potentially significantly affect the evolution of output.

Let us now show how bounded rationality and strategic complementarity interact to generate these policy effects. The extent of policy effectiveness can be assessed in many ways. We consider two: the derivative of the output response coefficient with respect to $\beta$, and the derivative of output variance with respect to $\beta$.

The policy parameter, $\beta$, influences the output response coefficient. Therefore, a simple way to assess the relationship between policy effectiveness and the degree of strategic complementarity is to see how the output response coefficient is affected by changes in $\beta$, for varying degrees of strategic complementarity. This is done in figure 2 , which illustrates several noteworthy points. First, we see again that if all agents form rational expectations $(\eta=0)$, then, irrespective of the degree of complementarity, the output response coefficient is not affected by policy changes. Second, for fixed nonzero $\eta$, the output response coefficient becomes 
increasingly more responsive to changes in $\beta$ as $s$ increases. Finally, for fixed $s$, the output response coefficient becomes increasingly more responsive to changes in $\beta$ as s increases.

Perhaps a more common way to assess policy effectiveness is to analyze the extent to which changes in policy affect the variance of output (e.g., Sargent, 1987). This is done in figure 3 , in which we plot the derivative of output variance with respect to $\beta$. For $\eta=0$, policy is ineffective, regardless of $s$, For fixed $\eta>0$, policy effectiveness is increasing in $s$. For fixed $s$, policy effectiveness is increasing in $\eta .^{10}$

Persistence. We have intentionally made our model simple enough so that the backward-looking nature of the non-rational expectations are the only source of persistent deviations of output from its trend. We will show that the stronger the degree of strategic complementarity, the stronger the persistence induced by rule-of-thumb forecasting. This can be seen in figure 4 , where we assess persistence as the first-order serial correlation coefficient of output. ${ }^{11}$ The regressive nature of the rule-of-thumb expectations works to produce positive serial correlation in output, despite the counter-cyclical monetary feedback rule. Furthermore, the extent of serial correlation in output is increasing in the degree of strategic complementarity in the economy. This result is consistent with one advanced by Oh and Waldman $(1990,1994)$, who also find a positive relationship between complementarity and persistence. Figure 4 also highlights the importance of interaction between complementarity and bounded rationality; significant positive serial

${ }^{10}$ Note that the derivative plotted in figure 3 is evaluated for a particular value of the policy parameter $(\beta=-.2)$. Thus it is not unusual that a negative relationship between $\beta$ and the variance of output is depicted. This just suggests that a larger value of $\beta$ is needed to minimize output variance.

${ }^{11}$ A richer dynamic analysis is performed in section 4 . 
correlation can be generated only when both factors are present. Again, we see strategic complementarity acting to magnify the frictions created by the rule-of-thumb expectations.

\subsection{The Magnifying Effects of Strategic Complementarity}

In analyzing the effectiveness of monetary policy and the persistence of output, we showed that strategic complementarity generated multipliers that had the effect of amplifying the aggregate impact of boundedly-rational expectations. The key to understanding the nature of this magnifying effect lies in the interactions between agents with rational and rule-of-thumb expectations.

Disproportionate Effect of Rule-of-Thumb Agents. This property of the model is very much in the spirit of Haltiwanger and Waldman (1989): when both rational and rule-of-thumb expectational behaviors are present, the rule-of-thumb expectations are disproportionately important. First, let us show this algebraically. Note that, if strategic complementarity exists and expectations are universally based on the rule of thumb ( $s>0, \eta=1)$, then equilibrium output is

$$
Y_{1}=\left[(\gamma(\beta-1) /(1+\gamma)] P_{t-1}+\gamma z_{1}+e_{t} .\right.
$$

Now suppose the rule-of-thumb expectations have just a proportionate effect on the behavior of the economy. Then it is the case that, for given realizations of $P_{t-1}, z_{l}$, and $e_{t}$, equilibrium output in (6") is just a linear combination of output under (7) and (8) with weights $1-\eta$ and $\eta$, respectively. On the other hand, rule-of-thumb expectations are disproportionately important if, for $0<\eta<1$,

$$
(8)>(7) \Leftrightarrow=>\left(6^{\prime \prime}\right)>[\eta(8)+(1-\eta)(7)]
$$

and

$$
(8)<(7) \Leftrightarrow\left(6^{\prime \prime}\right)<[\eta(8)+(1-\eta)(7)] \text {. }
$$


But (9) is true only if $[1 /(1+\gamma \eta)]-[1 /(1+\gamma)]>0$, which is true for all admissible $\gamma$ and $\eta$.

To gain some further insight on the relationship between strategic complementarity and the more-than-proportional impact of boundedly-rational expectations, we manipulate (9). This reduces the study of disproportionality to analyzing the magnitude of the output's response to lagged prices. From the right-hand-side of (12), we build the ratio

$$
\frac{\text { coefficient of } P_{t-1} \text { in (6") }}{\eta\left(\text { coefficient of } P_{t-1} \text { in (8)) }+(1-\eta)\left(\text { coefficient of } P_{t-1}\right. \text { in (7)) }\right.}
$$

which we call the relative output response to lagged prices. The greater the disproportionality associated with bounded rationality, the more the ratio will exceed one. Figure 5 plots this ratio as a function of $s$ for various values of $\eta$. It is clear from the figure that as the degree of complementarity increases, so does the relative importance of boundedly-rational expectations. This is evidenced by the fact that, for given $\eta$, the relative output response to lagged price increases with $\mathrm{s}^{12}$

The intuition behind the algebraic results derived above is straightforward. As paradoxical as it may seen, the model-consistent expectations of the sophisticated forecasters lead them, under strategic complementarity, to adopt a behavior that reinforces the misconceptions of the rule-ofthumb forecasters. For instance, the sophisticated forecasters are not "fooled" by anticipated changes in monetary policy, but they know that the rule-of-thumbers are. Accordingly, they incorporate this knowledge when forming their own expectations. Thus, because strategic

\footnotetext{
${ }^{12}$ Note that our model is such that even in the absence of complementarity, the agents with rule-of-thumb expectations are disproportionally important. Complementarity increases this disproportionality, however. Also, the fact that the curve in figure 5 shifts up as $\eta$ decreases is merely a consequence of the definition of the relative response to lagged price, which has $\eta$ times the output response coefficient of (8) appearing as the denominator.
} 
complementarity makes it optimal to increase one's own production when aggregate output is high, even the sophisticated forecasters end up producing more when there is a systematic increase in the money supply. The sophisticated forecasters respond not to the policy action per $s e$, but to the misguided reactions of the rule-of-thumb forecasters. Therefore, the model is such that sophisticated agents forecast the forecast of others. ${ }^{13}$

\section{Dynamic Response}

\subsection{Autoregressive Representation}

Our discussion thus far has been largely static in flavor. To understand the dynamics of our model in greater detail, we find its vector-autoregressive representation, from which we obtain and study its impulse-response functions.

The basic four-equation model is given by $\left(3 a^{\prime \prime}\right),(3 b),(3 c)$ and $\left(3 d^{\prime}\right)$, which we restate for convenience:

$$
\begin{gathered}
\mathrm{Y}_{\mathrm{t}}=\gamma\left(\mathrm{P}_{1}-\mathrm{P}_{\mathrm{t}}^{\mathrm{e}}\right)+\mathrm{e}_{\mathrm{t}} \\
\mathrm{M}_{\mathrm{t}}-\mathrm{P}_{\mathrm{t}}=\mathrm{Y}_{\mathrm{t}}+\mathrm{v}_{\mathrm{t}} \\
\mathrm{M}_{\mathrm{t}}=\beta \mathrm{P}_{\mathrm{t}-1}+\mathrm{w}_{\mathrm{t}}, \quad|\beta|<1 \\
\mathrm{P}_{\mathrm{t}}^{\mathrm{e}}=(1-\eta) \mathrm{E}\left(\mathrm{P}_{\mathrm{t}} \mid \mathrm{I}_{\mathrm{t}-1}\right)+\eta \mathrm{P}_{\mathrm{t}-1}, \quad 0 \leq \eta \leq 1 .
\end{gathered}
$$

Solving the model for $\mathrm{P}_{\mathrm{t}}^{\mathrm{e}}$ and inserting this solution in (3a") yields

$$
Y_{t}=\gamma\left(P_{t}-[(\beta+\eta(1+\gamma-\beta)) /(1+\gamma \eta)] P_{t-1}\right)+e_{t}
$$

Thus, we have a first-order, three-variable system in the variables of interest ( $Y, P$ and $M)$,

${ }^{13}$ This forecasting-the-forecast-of-others is made explicitly in equation (4"). In addition, as agents attempt to predict each other's expectations, they are implicitly forming expectations about the aggregate level of production. 


$$
\Phi_{1} X_{1}+\Phi_{2} X_{t-1}=\omega_{1}^{*}
$$

where $X_{1}=\left(Y_{v}, P_{b}, M_{1}\right)^{\prime}, \omega_{1}^{*}=\left(e_{1}, v_{1}, w_{t}\right)^{\prime}, \omega_{i}^{*} \sim(0, \Sigma)$, and

$$
\begin{gathered}
\Phi_{1}=\left[\begin{array}{ccc}
1 & -\gamma & 0 \\
-1 & -1 & 1 \\
0 & 0 & 1
\end{array}\right] \\
\Phi_{2}=\left[\begin{array}{ccc}
0 & \frac{\gamma \beta+\gamma \eta(1+\gamma-\beta)}{1+\gamma \eta} & 0 \\
0 & 0 & 0 \\
0 & -\beta & 0
\end{array}\right] .
\end{gathered}
$$

Multiplication of (12) by $\Phi_{1}^{-1}$ yields the vector autoregressive representation,

$$
X_{1}=-\Phi_{1}^{-1} \Phi_{2} X_{1-1}+\Phi_{1}^{-1} \omega_{1}^{*}
$$

which we write as

$$
X_{t}=A X_{t-1}+C \omega_{t}
$$

with $A=-\Phi_{1}^{-1} \Phi_{2}$ and $C=\Phi_{1}^{-1} R$, where $R$ is a lower triangular matrix such that $R R^{\prime}=\Sigma$ and $\omega_{1} \sim$ $\mathrm{g}(0, \mathrm{I}) \cdot{ }^{14}$

\subsection{Impulse Response Functions}

Repeated back-substitution in the autoregressive form yields the moving-average representation,

${ }^{14}$ In models with correlated shocks, the Cholesky factor of $\Sigma$, and hence the normalized impulse response function, depends on the assumed ordering of the system. For simplicity, however, we maintain the assumption that the shocks are uncorrelated ( $\Sigma$ diagonal), so that the Cholesky factor is diagonal with entries equal to the square roots of the respective entries of $\Sigma$, implying that the impulse response function is invariant to ordering. 


$$
X_{t}=\sum_{\tau=0}^{\infty} A^{\tau} C \omega_{1-\tau} .
$$

The impulse-response function is the sequence of coefficient matrices $\left\{A^{\tau} C, \tau=0,1,2, \ldots\right\}$. To show the dynamic implications of bounded rationality and complementarity, we have plotted, in figures 6 to 8 , the impulse responses of output, money, and prices, for a unit supply shock. It is clear from the figures that strategic complementarity plays two important roles in the dynamics of our stylized economy:

(1) Strategic complementarity induces persistence. As complementarity increases, it takes longer for the system to return to its steady state after being shocked.

(2) Strategic complementarity magnifies the endogenous response to a shock at any point in time.

In short, complementarity amplifies the impact of shocks both inter- and intratemporally. ${ }^{15}$

Finally, recall that we abstracted from auto- and cross-correlation in the shock process.

By ruling out the possibility of serially correlated shocks -- or, for that matter, of any other persistence generating mechanism, such as intertemporal substitution in labor supply decisions, time-to-build technologies, and adjustment costs -- we have stacked the deck against ourselves in our attempt to show the relationship between complementarity and persistence generation. The virtue of this strategy is that it allows us to isolate the impact of complementarity in the analysis of the propagation mechanism. The cost, of course, is that, occasionally, values of s close to its upper bound are required to generate realistic amounts of persistence. Were we to incorporate

\footnotetext{
${ }^{15}$ As shown above, bounded rationality is a necessary condition for the intertemporal effect to exist.
} 
serial and contemporaneous shock correlation, as is the norm in the empirical macroeconomics literature, much smaller values of $s$ would suffice.

\section{Summary and Concluding Remarks}

We have introduced strategic complementarity into an otherwise simple, stylized and admittedly ad hoc aggregative economic model. We have intentionally worked with this model, the goal being to use it to illustrate starkly the non-robustness of the policy-ineffectiveness and related classical propositions to potentially small violations of the rational expectations assumption, when strategic complementarity is present. It is our hope that, just as Sargent and Wallace (1975) used their model to make clear the macroeconomic effects of the main thrust in economic theory of the 1970s (rational expectations), so too will our results make clear the effects of an equally important but more recent thrust in economic theory (strategic complementarity).

Strategic complementarity amplifies the effects of even a small minority of rule-of-thumb agents, leading to policy effects, output persistence and multipliers. The Keynesian features arise because, although the rational agents cannot be fooled by anticipated money movements, they anticipate the behavior of the agents with suboptimal forecasts. Therefore, in the presence of strategic complementarity, they find it optimal to imitate their behavior.

Effectively, we have addressed the concerns of Ball, Mankiw and Romer (1988), Ball and Romer (1990), and others, who note that rules of thumb alone cannot explain the non-neutralities of money unless their use is pervasive and the resulting expectational errors large. We have argued that strategic complementarity is the missing ingredient. Our results complement those of 
Haltiwanger and Waldman (1991), whose analysis of forecast-heterogeneity is carried out within the context of a static model with real shocks. Ours is a dynamic aggregative model with both real and nominal shocks.

The model with sophisticated and rule-of-thumb agents may be thought of as an approximation to a model in which all agents are rational in the sense that their expectations are mathematical expectations, but conditional upon a much more restrictive information set. Such a framework would allow for the plausible possibility that it is costly to gather and process information (Evans and Ramey, 1992; Sethi and Franke, 1995). Moreover, it would have the advantage of addressing concerns related to the lack of microfoundations for the rule-of-thumb behavior analyzed here.

Finally, we note that our analysis may be interpreted as a theory of the underpinnings of supply response. That is, the introduction of $s$ is obviously observationally equivalent to increasing $\alpha$. Our results, therefore, may be interpreted as providing guidance in interpreting supply elasticities -- the coefficient of the price surprise in the aggregate supply function represents more than just the elasticity of individual supply functions with respect to changes in the relative price.

Moreover, although our key parameters $\alpha$ and s cannot be separately identified using aggregate data, the model is not devoid of empirical implications. In particular, it may be possible identify $\alpha$ and s separately using disaggregated data. It may prove fruitful, for example, to examine disaggregated supply functions to see whether, and how, aggregate activity enters. 


\section{References}

Akerlof, G. A. and Yellen, J. L. (1985a), "Can Small Deviations from Rationality Make Significant Differences to Economic Equilibria?," American Economic Review, 75, 708-720.

Akerlof, G. A. and Yellen, J. L. (1985b), "A Near-Rational Model of the Business Cycle With Wage and Price Inertia," Quarterly Journal of Economics, 100, 823-838.

Ball, L., Mankiw, N.G. and Romer, D. (1988), "The New Keynesian Economics and the Output-Inflation Tradeoff," Brookings Papers on Economic Activity, 1, 1-82.

Ball, L., and Romer, D. (1990), "Real Rigidities and the Non-Neutrality of Money," Review of Economic Studies, 57, 183-203.

Baxter, M. and King, R. (1991), "Productive Externalities and Cyclical Volatility," unpublished, University of Rochester.

Chatterjee, S., Cooper, R. and Ravikumar, B. (1993), "Strategic Complementarity in Business Formation: Aggregate Fluctuations and Sunspot Equilibria, Review of Economic Studies, $60,795-811$.

Cooper, R. and Haltiwanger, J. (1993), "Evidence on Macroeconomic Complementarities," NBER Working Paper \#4577.

Cooper, R. and John, A. (1988), "Coordinating Coordination Failures in Keynesian Models," Quarterly Journal of Economics, 103, 441-463.

Diamond, P.A. (1982), "Aggregate Demand Management in Search Equilibrium," Journal of Political Economy, 90, 881-894.

Evans, G. and Ramey, G. (1992), "Expectation Calculation and Macroeconomic Dynamics," American Economic Review, 207-224.

Haltiwanger, J. and Waldman, M. (1985), "Rational Expectations and the Limits of Rationality: An Analysis of Heterogeneity," American Economic Review, 75, 326-340.

Haltiwanger, J. and Waldman, M. (1989), "Limited Rationality and Strategic Complementarity: The Implications for Macroeconomics," Quarterly Journal of Economics, 104, 463-483.

Haltiwanger, J. and Waldman, M. (1991), "Responders Versus Nonresponders: A New Perspective on Heterogeneity," Economic Journal, 101, 1085-1102. 
Hart, O. (1982), "A Model of Imperfect Competition with Keynesian Features," Quarterly Journal of Economics, 97, 109-138.

Heller, W. (1986), "Coordination Failure Under Complete Markets with Applications to Effective Demand," in W. Heller, R. Starr, and D. Starrett (eds.), Equilibrium Analysis: Essays in Honor of Kenneth J. Arrow, Volume II. Cambridge: Cambridge University Press.

Lucas, R.E. (1972), "Expectations and the Neutrality of Money," Journal of Economic Theory, 4, 103-124.

Lucas, R.E. (1973), "Some International Evidence on Output-Inflation Tradeoffs," American Economic Review, 63, 326-334.

Lucas, R.E. (1975), "An Equilibrium Model of the Business Cycle," Journal of Political Economy, 83, 1113-1144.

Mankiw, N.G. (1985), "Small Menu Costs and Large Business Cycles: A Macroeconomic Model of Monopoly," Quarterly Journal of Economics, 100, 529-537.

Oh, S. and Waldman, M. (1990), "The Macroeconomic Effects of False Announcements," Quarterly Journal of Economics, 105, 1017-1034.

Oh, S. and Waldman, M. (1984), "Strategic Complementarity Slows Macroeconomic Adjustment to Temporary Shocks," Economic Inquiry, 32, 318-329.

Pagano, M. (1990), "Imperfect Competition, Underemployment Equilibria and Fiscal Policy," Economic Journal, 100, 440-463.

Sargent, T.J. (1987), Macroeconomic Theory (2nd. Edition). Orlando, FL: Academic Press.

Sargent, T.J. and Wallace, N. (1975), "'Rational' Expectations, the Optimal Monetary Instrument, and the Optimal Money Supply Rule," Journal of Political Economy, 83, 241-254.

Sethi, R., and Franke, R. (1995), "Behavioural Heterogeneity under Evolutionary Pressure: Macroeconomic Implications of Costly Optimization," Economic Journal, 105, 583-600.

Simon, H.A. (1982), Models of Bounded Rationality, Volume II. Cambridge, Mass.: MIT Press.

Townsend, R. (1983), "Forecasting the Forecast of Others," Journal of Political Economic, 91, 546-588. 


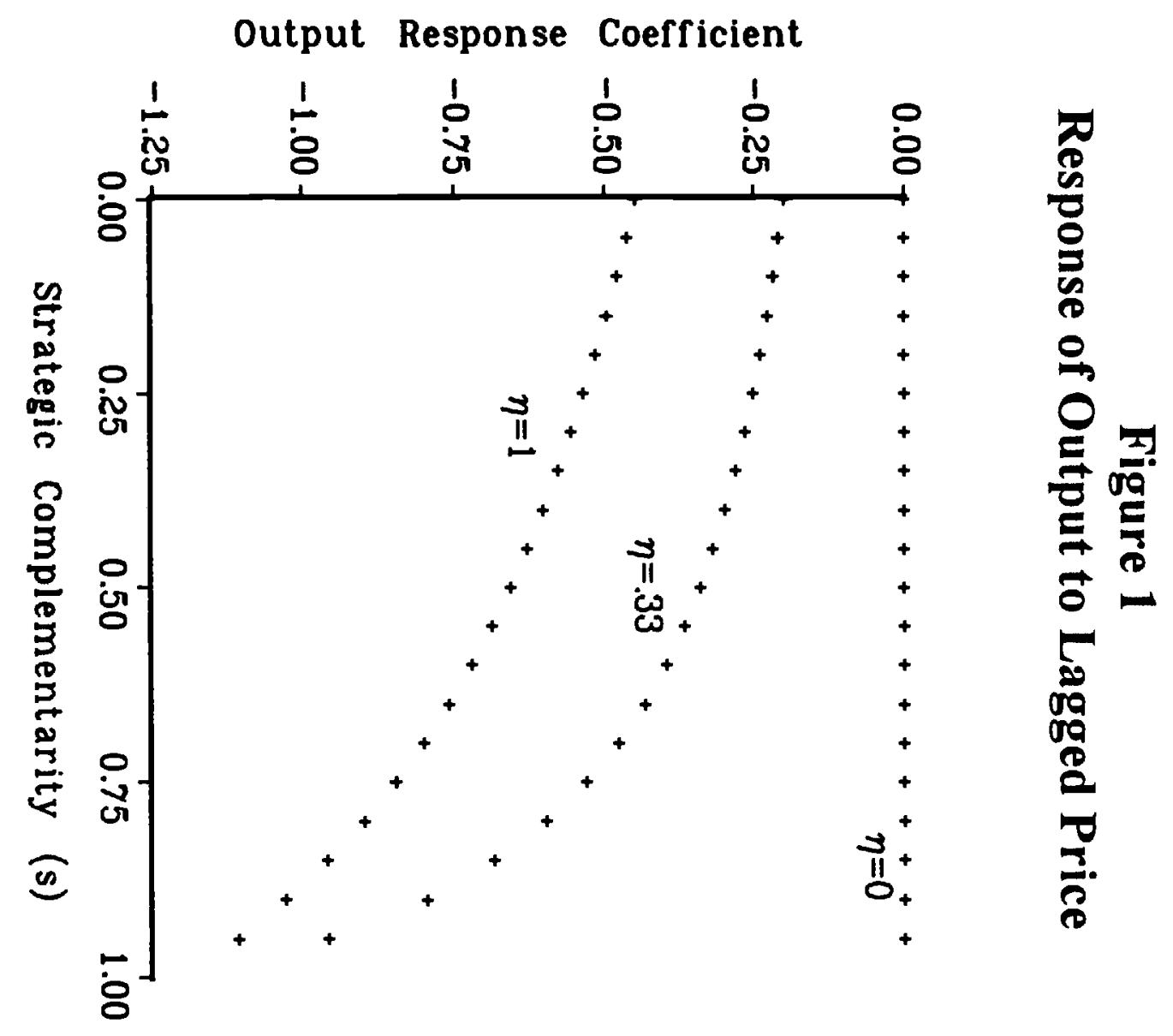


Figure 2

Derivative of Output Response Coefficient With Respect to $\beta$

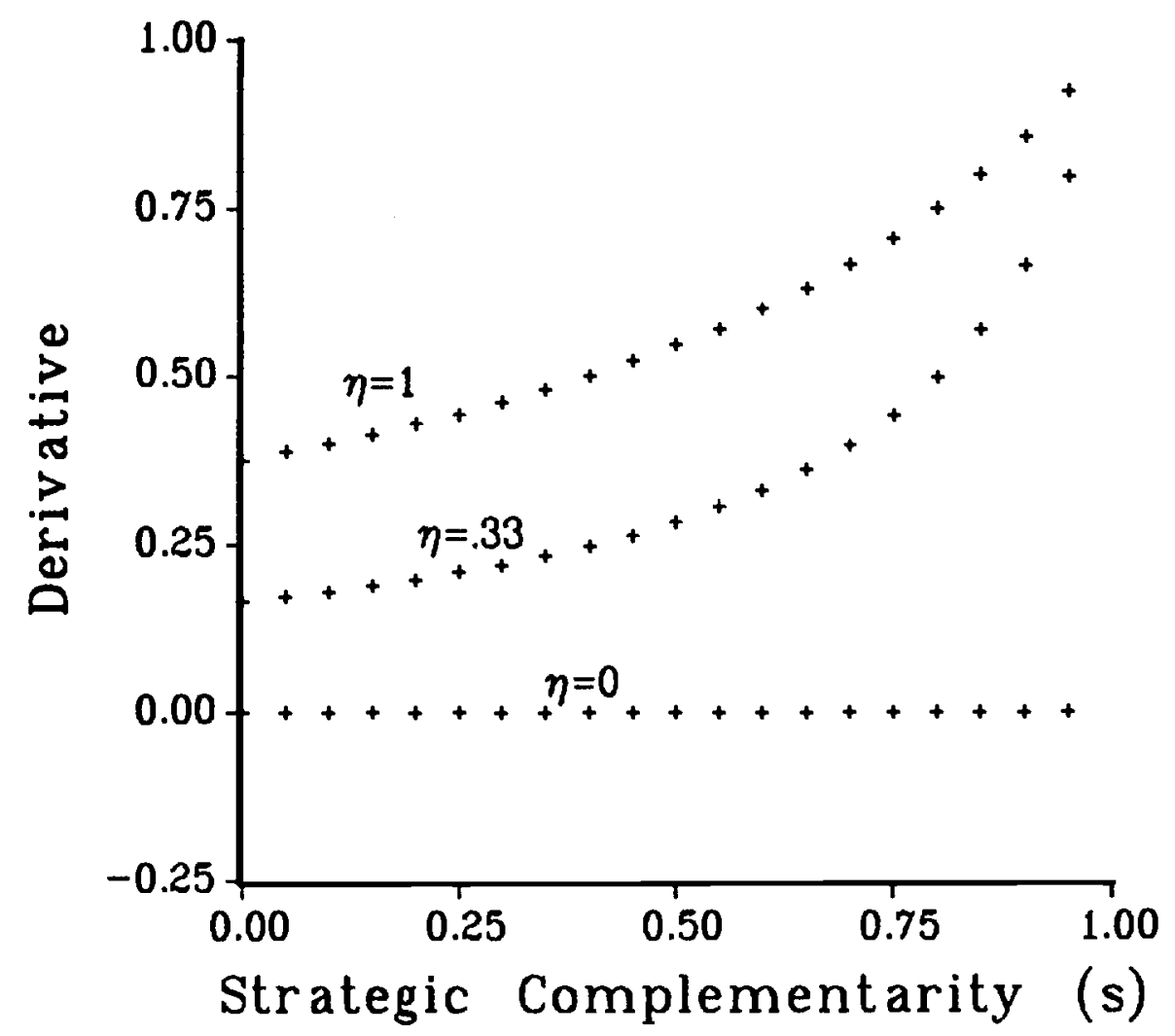


Figure 3

\section{Derivative of Output Variance with Respect to $\beta$}

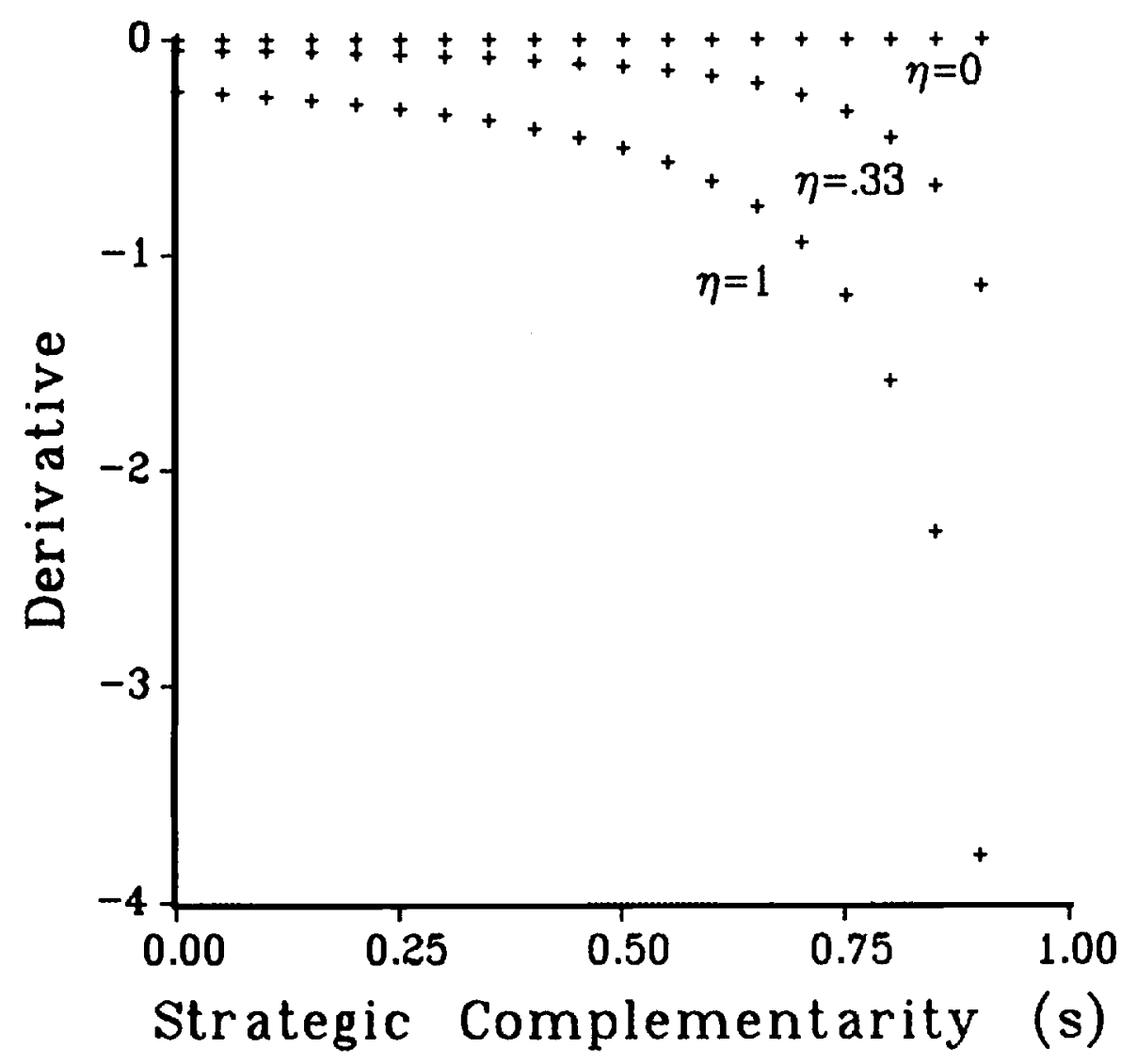


Figure 4

\section{Output Autocorrelation}

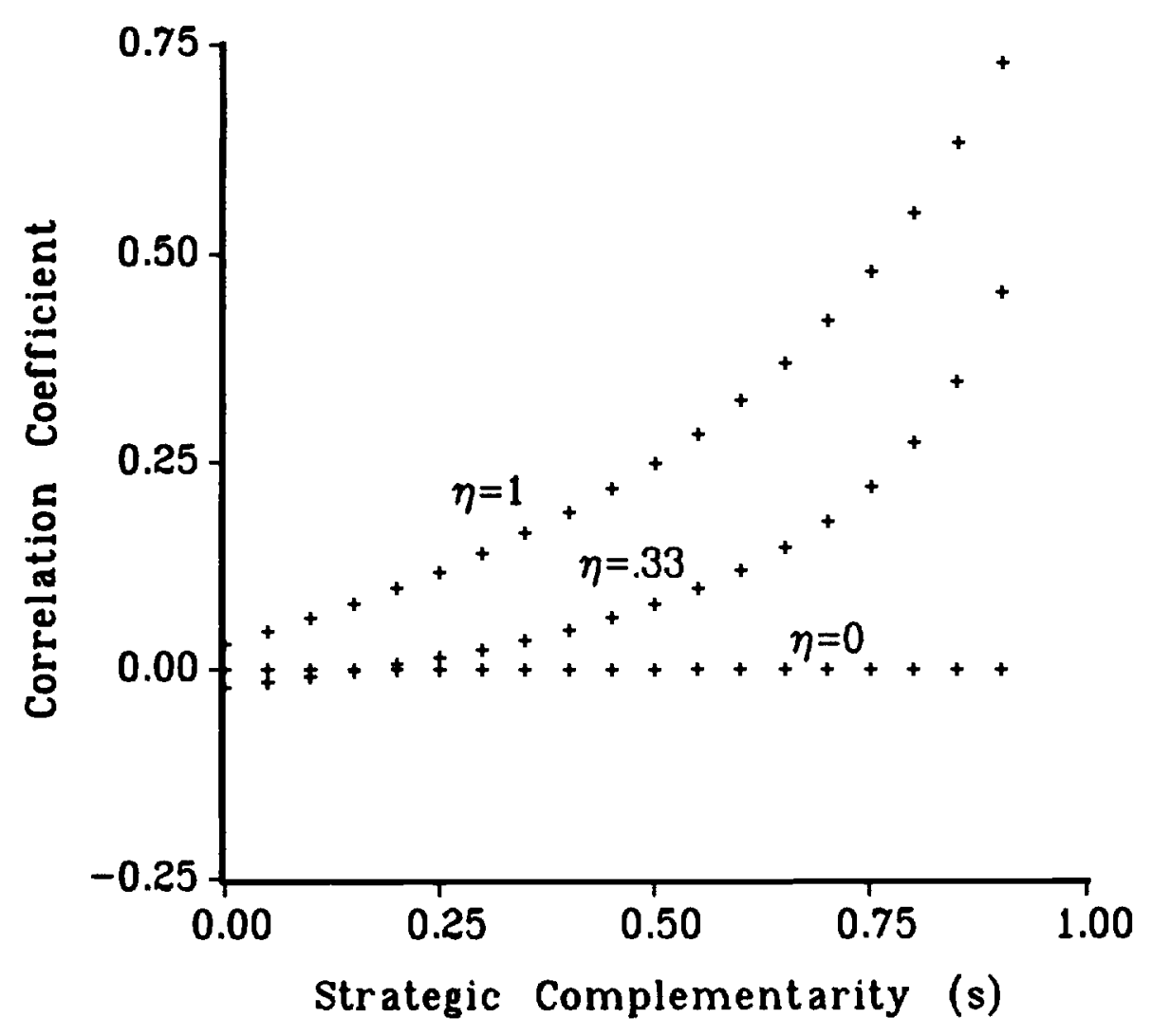


Figure 5

Relative Response of Output to Lagged Price

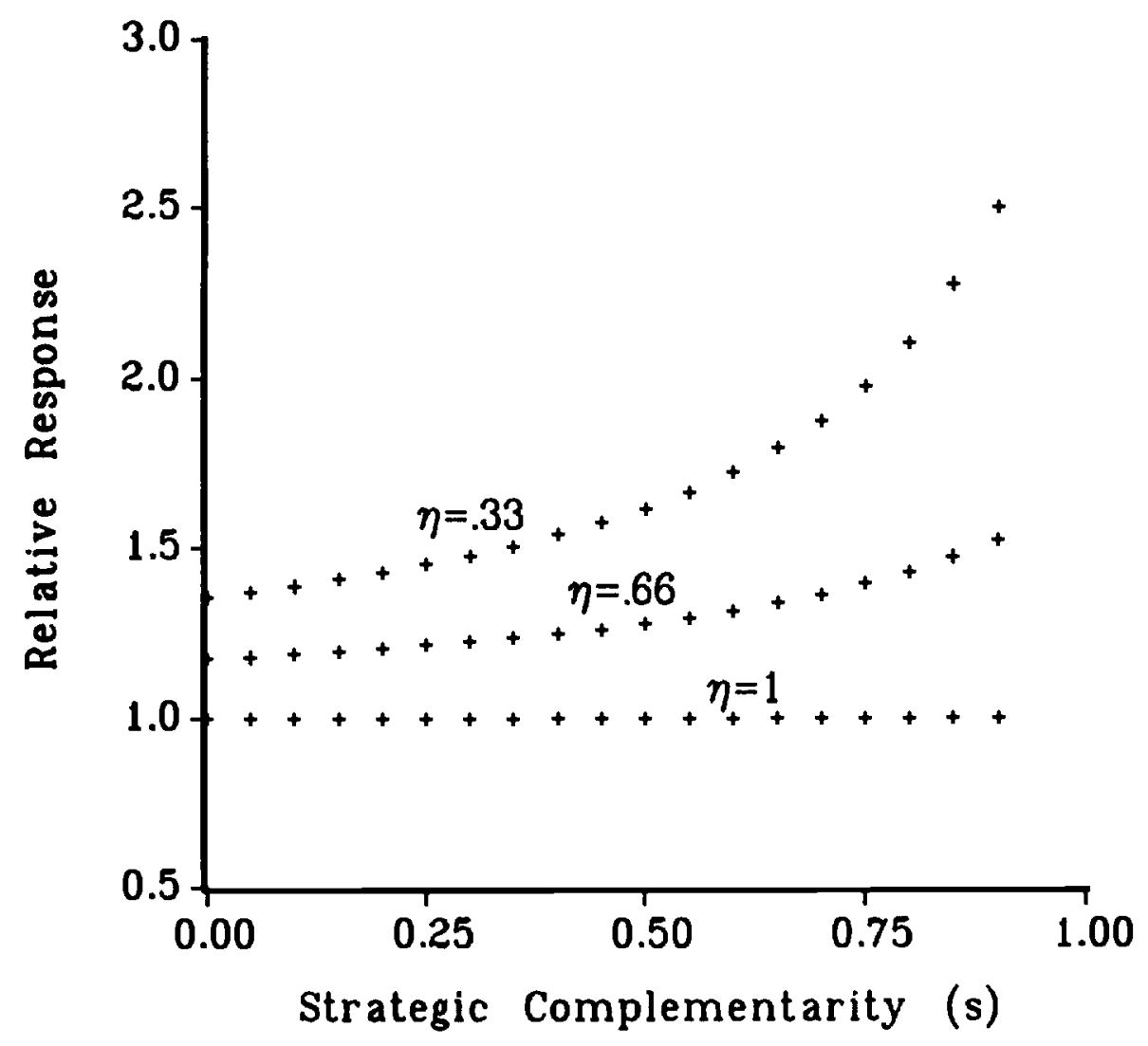


Figure 6

\section{Response of Output to a Unit Output Shock}
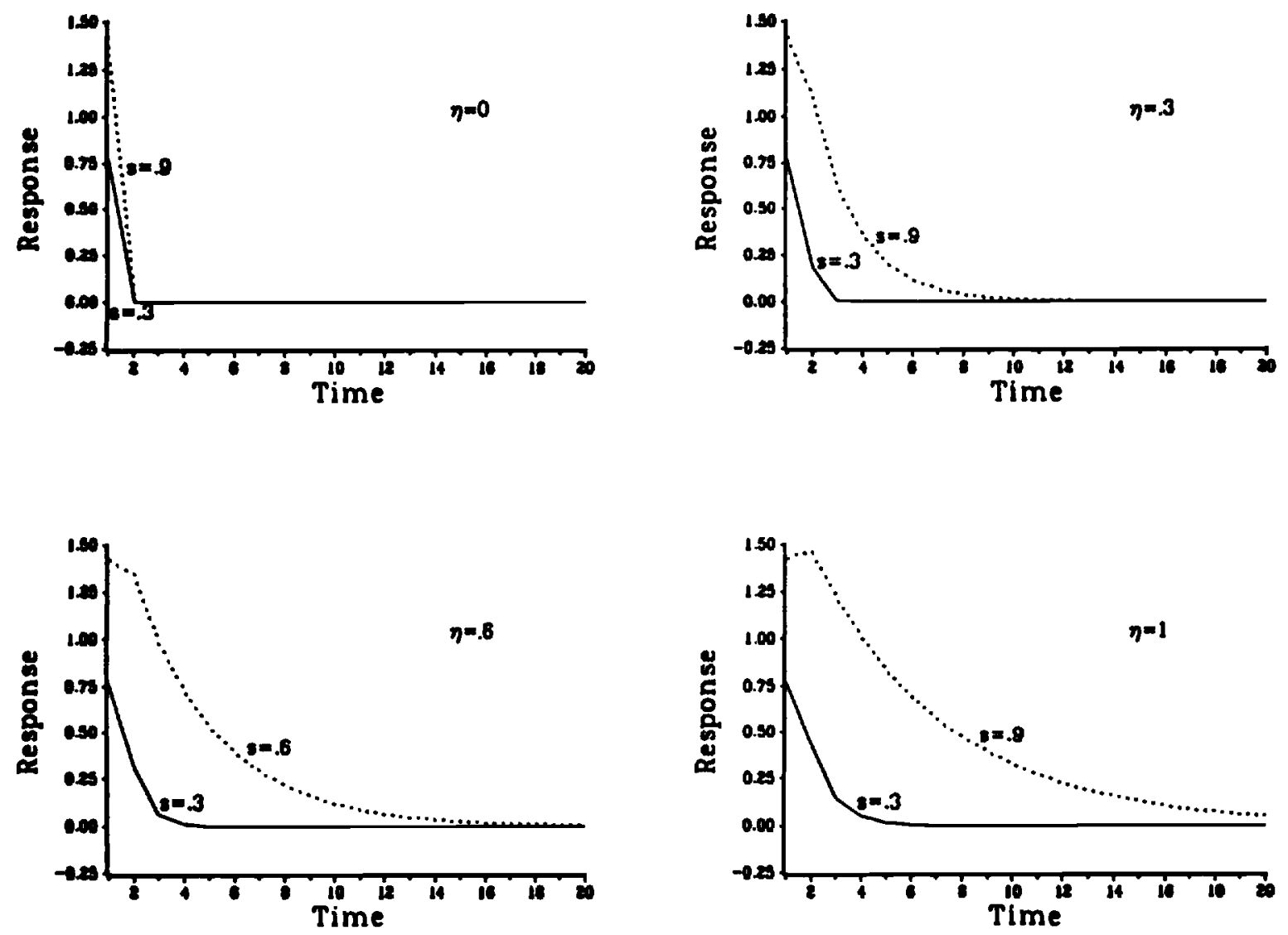
Figure 7

\section{Response of Money to a Unit Output Shock}
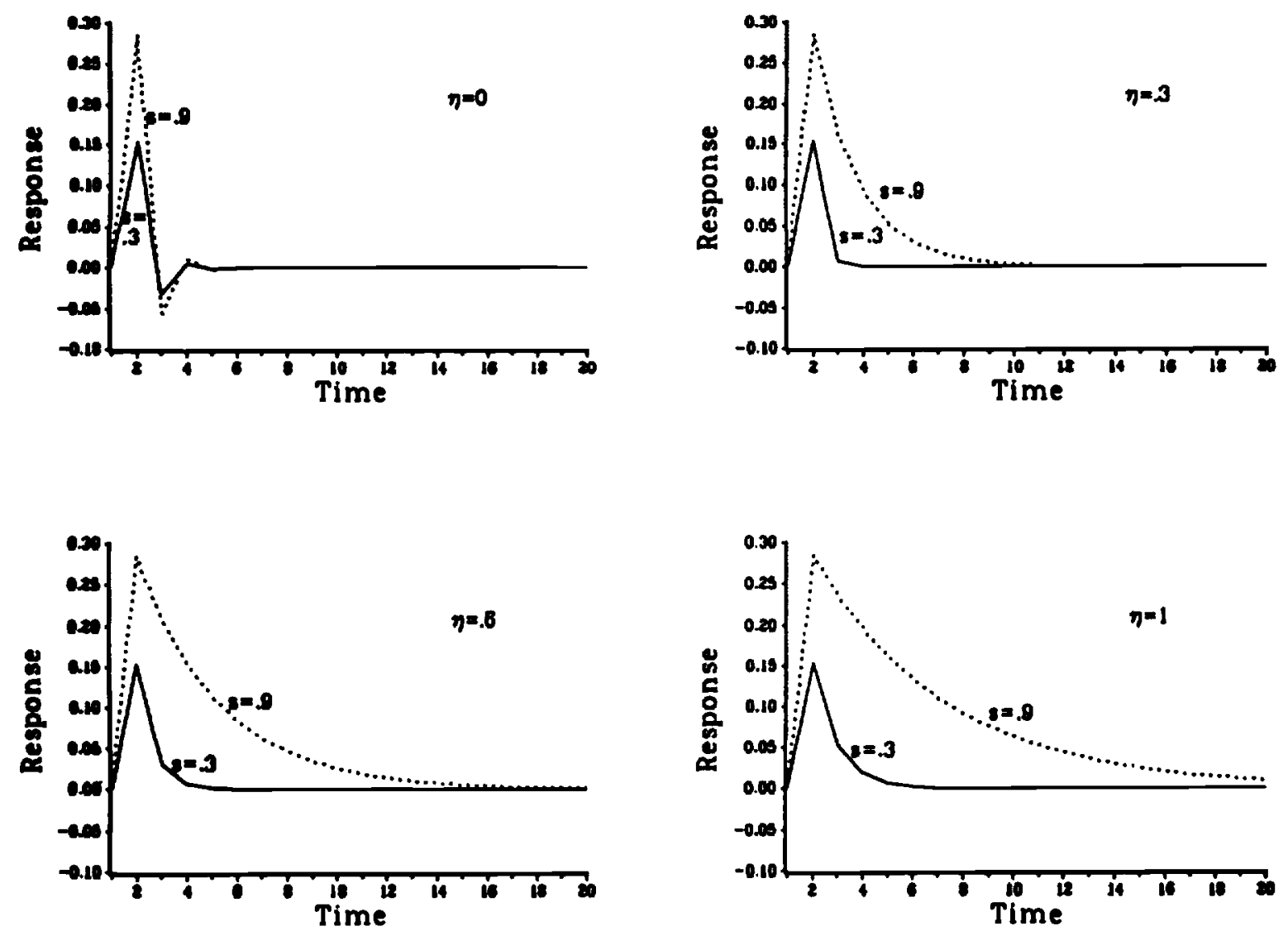
Figure 8

\section{Response of Prices to a Unit Output Shock}
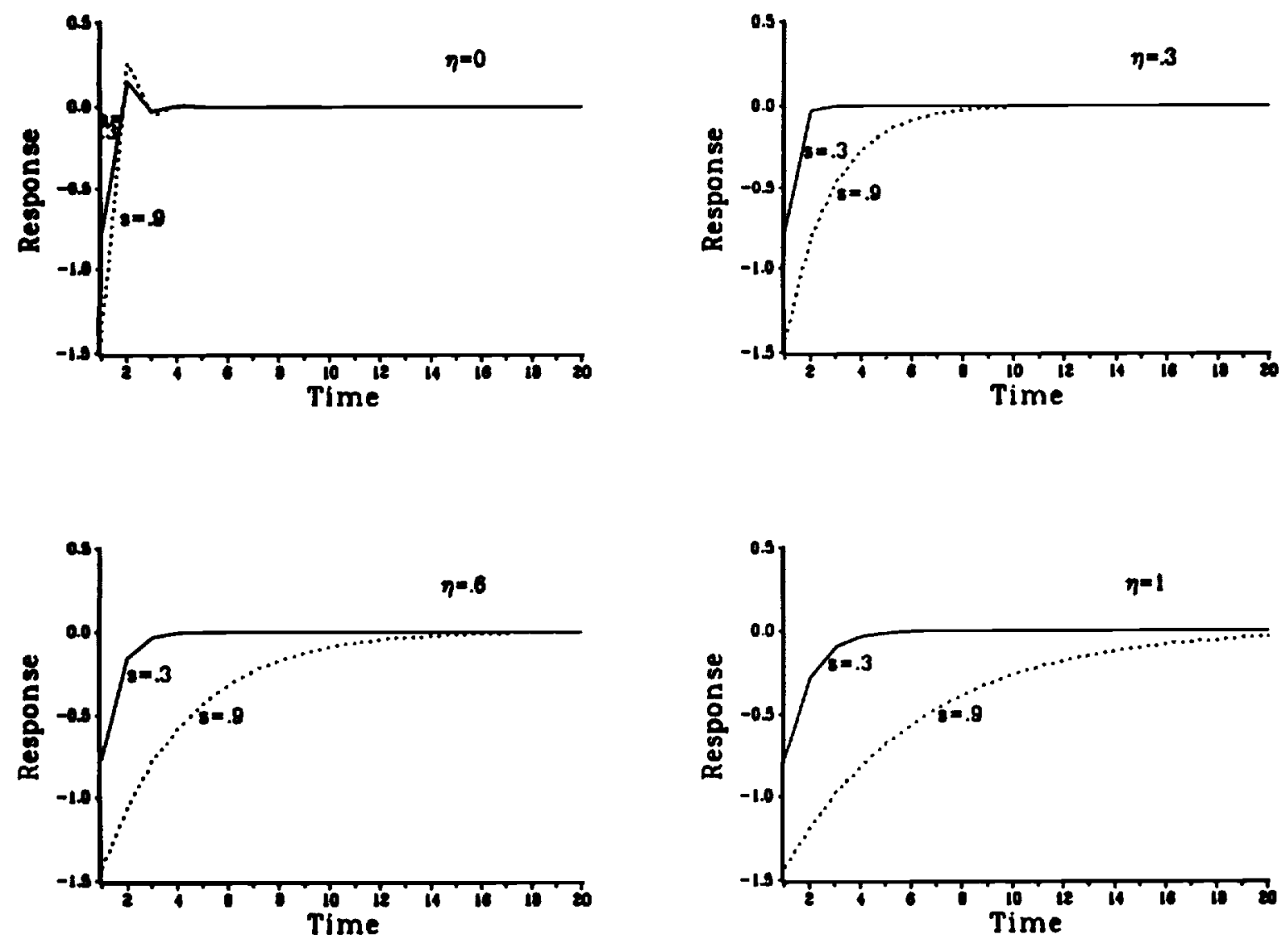